\title{
Analisis Korelasi Keterampilan Metakognitif dan Minat Belajar terhadap Hasil Belajar Siswa pada Materi Kesetimbangan Kimia
}

\author{
Lia Andini, Utiya Azizah* \\ Program Studi Pendidikan Kimia, Fakultas Matematika dan Ilmu Pengetahuan Alam \\ Universitas Negeri Surabaya \\ *Corresponding Author. Email: utiyaazizah@unesa.ac.id
}

\begin{abstract}
The purpose of this study was to analyze the correlation between metacognitive skills and learning interest in student learning outcomes in the sub-material equilibrium shift reaction. The method used is the descriptive correlation using test and questionnaire data collection techniques. The research subjects were 31 students of grade 11 IPA 6 at SMAN 1 Cerme in Gresik. Metacognitive skills data were obtained from metacognitive skills tests supported by MAI (Metacognitive Awareness Inventory) questionnaires, data on learning interest were obtained from questionnaires, and learning outcomes data were obtained from student learning outcomes tests. The analysis carried out is a statistical test. The tests conducted consisted of the Shapiro-Wilk normality test and hypothesis testing used multiple linear regression analysis. The result of this study shows positive and significant correlation between metacognitive skills and learning interest toward the students' learning outcomes both in partial and simultaneously in chemical equilibrium, submaterial shift of chemical equilibrium, the effects of the independent variable are $76,6 \%$, while other factors outside the research variables influenced the other $23.4 \%$.
\end{abstract}

\begin{abstract}
Abstrak: Tujuan penelitian ini adalah untuk menganalisis hubungan korelasional antara keterampilan metakognitif dan minat belajar terhadap hasil belajar siswa pada submateri pergeseran kesetimbangan. Penelitian ini menggunakan metode descriptive correlation menggunakan teknik pengumpulan data dengan cara tes dan angket. Subjek penelitian ini adalah siswa 11 IPA 6 SMAN 1 Cerme di Kabupaten Gresik, yaitu sebanyak 31 siswa. Data keterampilan metakognitif didapat dari tes keterampilan metakognitif yang didukung dengan angket MAI (Metacognitive Awareness Inventory), data minat belajar didapat dari angket dan data hasil belajar siswa didapat dari tes hasil belajar siswa. Analisis yang dilakukan adalah uji statistik. Uji yang dilakukan terdiri atas uji normalitas Shapiro-wilk, dan uji hipotesis dengan analisis regresi linier berganda. Hasil penelitian ini adalah terdapat korelasi positif dan signifikan antara keterampilan metakognitif dan minat belajar terhadap hasil belajar siswa pada materi kesetimbangan kimia submateri pergeseran kesetimbangan baik secara parsial maupun simultan, dengan pengaruh variabel independen sebesar 76,6\% sementara 23,4\% dipengaruhi oleh aspek lain diluar variabel penelitian yang digunakan.
\end{abstract}

\section{Article History}

Received: 03-01-2021

Revised: 25-02-2021

Accepted: 21-04-2021

Published: 07-06-2021

\section{Key Words:}

Metacognitive Skills, Learning Interest, Learning Outcomes.

\section{Sejarah Artikel}

Diterima: 03-01-2021

Direvisi: 25-02-2021

Disetujui: 21-04-2021

Diterbitkan: 07-06-2021

\section{Kata Kunci: \\ Keterampilan \\ Metakognitif, Minat \\ Belajar, Hasil Belajar.}

How to Cite: Andini, L., \& Azizah, U. (2021). Analisis Korelasi Keterampilan Metakognitif dan Minat Belajar terhadap Hasil Belajar Siswa pada Materi Kesetimbangan Kimia. Jurnal Kependidikan: Jurnal Hasil Penelitian dan Kajian Kepustakaan di Bidang Pendidikan, Pengajaran dan Pembelajaran, 7(2), 472-480. doi:https://doi.org/10.33394/jk.v7i2.3327

d. https://doi.org/10.33394/jk.v7i2.3327

This is an open-access article under the CC-BY-SA License.

\section{Pendahuluan}

Kimia adalah mata pelajaran yang diajarkan di jenjang Sekolah Menengah Atas (SMA). Kimia menekankan siswa untuk mempelajari konsep secara runtut, terstruktur dan 
rinci (Amanda et al., 2020). Kimia berisi berbagai konsep, fakta, dan teori yang beruhubungan dengan hitungan dan reaksi kimia yang cukup sulit untuk dipahami siswa (Mustapa et al., 2017). Proses pembelajaran yang ideal akan sangat membantu pemahaman siswa dalam mata pelajaran kimia.

Proses pembelajaran merupakan perubahan dalam diri pebelajar setelah selesainya kegiatan belajar (Amin et al., 2018). Pendapat lain menyatakan bahwa proses pembelajaran sebagai suatu proses untuk mencari, mengenali, menemukan dan mengambil keputusan pada apa yang dipelajari, serta menimbulkan perubahan terhadap perkembangan pribadi seseorang, diantara nya dapat berupa perubahan tingkah laku dan mental spiritualnya (Abdullah, 2017). Pada proses pembelajaran siswa diharuskan untuk aktif dalam mencari, menemukan dan menggunakan pengetahuannya agar dapat memahami suatu konsep dengan atau tanpa bantuan guru selama proses belajar berlangsung (Sinaga \& Silaban, 2020). Berdasarkan uraian di atas, proses pembelajaran melibatkan keterampilan berpikir siswa dalam mencari, menemukan, dan menggunakan pengetahuannya untuk memahami suatu konsep dari informasi atau pengetahuan yang berakibat adanya perubahan terhadap perkembangan pribadi seseorang.

Salah satu keterampilan berpikir yang dapat meningkatkan pemahaman siswa selama proses pembelajaran yaitu keterampilan metakognitif. Keterampilan metakognitif merupakan aktivitas mental dalam struktur kognitif yang secara sadar mengatur, mengendalikan, dan memeriksa proses berpikir seseorang (Azizah et al., 2019). Pendapat lain menyatakan bahwa metakognisi merupakan pemahaman seseorang mengenai proses berpikirnya dan bagaimana mengatur proses tersebut (Jayapraba \& Kanmani, 2013). Siswa dengan pengetahuan metakognitif baik, akan memahami kelebihan dan kekurangannya selama belajar, sehingga dapat mengetahui kesalahan selama belajar dan berusaha memperbaikinya (Iskandar, 2014). Melalui keterampilan metakognitif yang dimiliki, siswa dapat mengontrol diri selama proses belajarnya, keterampilan tersebut dapat mendukung proses pembelajaran yang terfokus pada siswa (Mahmuda \& Azizah, 2020). Siswa dengan metakognitif yang terlatih dengan baik akan mengerti bagaimana proses belajar yang baik untuk dirinya, sehingga siswa dapat mengontrol dan mengevaluasi proses pembelajarannya.

Proses pembelajaran juga dipengaruhi oleh faktor internal dan faktor eksternal. Faktor internal terdiri dari, motivasi, perhatian, minat, bakat, intelegensi, dan cara belajar. Faktor eksternal terdiri dari, lingkungan keluarga, sekolah, dan masyarakat (Hemayanti et al., 2020). Minat belajar diartikan sebagai kemauan dan keterlibatan pada kegiatan kognitif yang memiliki peran penting pada proses pembelajaran, memilih bagian untuk dipelajari, dan seberapa baik dalam mempelajari materi atau pengetahuan yang diberikan (Klassen \& Klassen, 2014). Minat belajar menjadi faktor terpenting untuk mendorong keberhasilan belajar karena menciptakan ingatan yang baik untuk siswa (Olufemi Adodo \& L. O. Gbore, 2012). Minat belajar juga dapat memengaruhi interpretasi siswa terhadap materi yang diberikan guru dan memengaruhi nilai siswa pada akhir proses pembelajaran (Laa et al., 2017). Minat belajar kimia siswa yang kurang dan materi yang cukup sulit dapat mempengaruhi hasil belajarnya (Saputri et al., 2018).

Hasil belajar merupakan hasil dari suatu proses pembelajaran. Hasil belajar diartikan sebagai hal yang mendasar untuk menilai dan melaporkan capaian belajar siswa, serta untuk pengembangan metode pembelajaran yang lebih efektif dan mempunyai kesesuaian antara materi yang dipelajari siswa dan bagaimana siswa dinilai (Abu-Hamdan \& Khader, 2014). Hasil belajar juga sebagai salah satu tolok ukur dalam ketercapaian pembelajaran, 
diindikasikan oleh sejauh mana pencapaian siswa, pendidik, proses belajar, dan lembaga pendidikan dalam upaya pencapaian tujuan pendidikan (Kpolovie, 2014). Pendapat lain menyatakan bahwa hasil belajar merupakan pengetahuan dan keterampilan dalam diri siswa yang dimilikinya setelah proses pembelajaran (Mølstad \& Karseth, 2016). Hasil belajar mencakup tiga bidang yaitu, kognitif, afektif dan psikomotorik. Bidang kognitif memfokuskan pada pengetahuan akademik siswa melalui proses pembelajaran, bidang afektif memfokuskan pada sikap, nilai, dan keyakinan siswa, dan bidang psikomotorik memfokuskan pada kecakapan serta peningkatan kemampuan siswa yang dilaksanakan dengan kinerja keterampilan ataupun praktek (Straus et al., 2013).

Ranah kognitif merupakan kemampuan yang harus dikuasai oleh siswa, karena merupakan dasar bagi penguasaan ilmu pengetahuan. Salah satu materi kimia yang harus dikuasai siswa adalah kesetimbangan kimia. Namun hasil angket pra-penelitian yang disebar kepada siswa kelas 12 IPA 5 di SMAN 1 Cerme menemukan bahwa sebanyak 83,87\% siswa mengalami kesulitan pada materi kesetimbangan kimia, kesulitan tersebut meliputi submateri definisi reaksi kesetimbangan 12,90\%, submateri pergeseran kesetimbangan 29,03\%, submateri tetapan kesetimbangan $22,58 \%$, siswa lupa $12,90 \%$, ragu-ragu $19,35 \%$, dan siswa paham materi kesetimbangan kimia $3,22 \%$. Rendahnya pemahaman siswa antara lain disebabkan karena adanya hambatan ketika pembelajaran kimia berlangsung, untuk itu perlu adanya strategi belajar yang sesuai agar pemahaman siswa maksimal dan hasil belajar siswa meningkat. Dengan keterampilan metakognitif siswa akan mampu membangun pengetahuan sendiri, menentukan strategi yang akan digunakan untuk pemecahan masalah, dan mampu mengontrol hasil belajar. Keterampilan metakognitif yang berkembang dengan baik membuat siswa menyadari kekuatan dan kelemahannya dalam belajar yang berdampak pada minat yang kuat untuk belajar, sehingga diharapkan hasil belajar siswa menjadi lebih baik.

Penelitian dari Mustapa et al., (2017) menyebutkan bahwa kesadaran metakognisi berkorelasi positif dengan hasil belajar kimia siswa, tes hasil belajar diambil dari nilai ratarata ulangan harian semester ganjil. Indikator keterampilan metakognitif yang diujikan yaitu pengetahuan deklaratif, pengetahuan prosedural, pengetahuan kondisional, perencanaan, strategi manajemen informasi, monitoring pemahaman, strategi debugging, dan evaluasi belajar. Penelitian lain juga menyebutkan bahwa minat belajar dan hasil belajar kimia siswa saling berkorelasi positif dan signifikan (Amin et al., 2018), artinya siswa dengan keterampilan metakognitif dan minat belajar yang baik, hasil belajarnya juga akan maksimal, dijelaskan variabel minat belajar berpengaruh sebesar 26,83\% terhadap hasil belajar siswa, sedangkan sebesar 73,13\% dipengaruhi oleh faktor-faktor lain yang tidak diteliti dalam penelitian tersebut, aspek minat belajar yang diteliti yaitu rasa tertarik, perhatian, partisipasi, keinginan atau kesadaran.

Berdasarkan uraian diatas, penelitian ini bertujuan untuk menganalisis hubungan korelasional antara keterampilan metakognitif dan minat belajar terhadap hasil belajar siswa pada submateri pergeseran kesetimbangan.

\section{Metode Penelitian}

Metode penelitian yang digunakan dalam penelitian ini adalah descriptive correlation. Data kemudian di analisis secara kuantitatif yang bertujuan untuk menyatakan hubungan antar variabel, menggunakan instrumen penelitian, dan desain penelitian salah satunya yaitu uji hipotesis yang sudah ditentukan (Sugiyono, 2012). Penelitian dilakukan pada siswa XI IPA 6 SMAN 1 Cerme, yang berjumlah 31 siswa. Data didapatkan dengan metode tes dan 
angket. Variabel independen yang diukur yaitu keterampilan metakognitif $\left(\mathrm{X}_{1}\right)$ dan minat belajar kimia siswa $\left(\mathrm{X}_{2}\right)$, sedangkan variabel dependen berupa hasil belajar kimia pada materi kesetimbangan kimia submateri pergeseran kesetimbangan (Y). Berikut adalah model dalam penelitian ini :

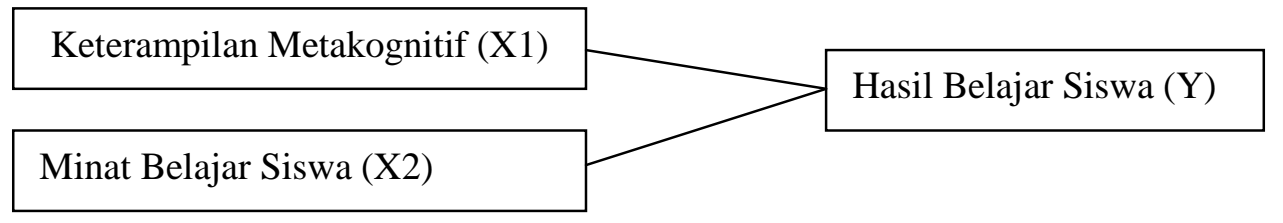

\section{Gambar 1. Model Penelitian}

Data keterampilan metakognitif siswa didapatkan dari tes dengan tiga komponen keterampilan metakognitif, terdiri dari planning skills, monitoring skills, dan evaluating skills, dan diperkuat dengan angket inventori metakognitif atau MAI (Metacognitive Awareness Inventory) yang berfokus pada tiga komponen serupa, diadaptasi dari (Schraw \& Dennison, 1994). MAI berisi pertanyaan positif dan pertanyaan negatif, kemudian dikonversi dalam skala likert dengan 4 pilihan jawaban. Indikator keterampilan metakognitif pada penelitian ini adalah menuliskan tujuan belajar, memikirkan dan menuliskan yang diketahui dan tidak diketahui, memecahkan masalah tambahan dan memeriksa ulang tujuan belajar apakah sudah tercapai semua (Pulmones, 2007).

Data minat belajar siswa diambil dari angket yang berisi pertanyaan positif dan negatif adaptasi dari (iskandar, 2001), kemudian dikonversi dalam skala likert dengan 4 pilihan jawaban. Indikator-indikator minat belajar meliputi ketertarikan dalam membaca buku kimia, perhatian belajar kimia, keaktifan siswa saat pelajaran kimia, dan pengetahuan kimia siswa (iskandar, 2001). Pedoman penskoran menggunakan skala Likert berdasarkan Tabel 1.

\section{Tabel 1. Pedoman Penskoran dengan Skala Likert}

\begin{tabular}{lcc}
\hline \multicolumn{1}{c}{ Frekuensi } & Poin Pertanyaan positif & Poin Pertanyaan negatif \\
\hline Selalu (S) & 4 & 1 \\
Sering (SR) & 3 & 2 \\
Jarang (JR) & 2 & 3 \\
Tidak pernah (TP) & 1 & 4 \\
\hline
\end{tabular}

(Sugiyono, 2012)

Tes hasil belajar berisi soal pilihan ganda yang memuat pengetahuan siswa pada materi yang diujikan. Skor yang diperoleh kemudian dikategorikan sebagai berikut : $0-20=$ sangat rendah, $21-40=$ rendah, $41-60=$ sedang, $61-80=$ baik, dan $81-100=$ sangat baik. (Riduwan, 2011). Data hasil penelitian kemudian di analisis dengan uji statistik, diantaranya yaitu uji normalitas Shapiro-wilk, dan uji hipotesis dengan analisis regresi linier berganda.

\section{Hasil Penelitian dan Pembahasan}

Data diperoleh dari tes dan angket yang disebar pada 31 responden siswa kelas XI SMAN 1 Cerme, kemudian dianalisis dengan software SPSS 25. Data keterampilan metakognitif diperoleh dari tes berisi soal esay yang terintegrasi dengen keterampilan metakognitif pada content submateri pergeseran kesetimbangan dan angket MAI, minat belajar diperoleh dari angket, dan hasil belajar dari tes hasil belajar pada submateri pergeseran kesetimbangan, sehingga dihasilkan data olah berikut ini. 


\section{Uji Normalitas}

Uji normalitas Shapiro-Wilk menunjukkan signifikasi keterampilan metakognitif sebesar 0,199, minat belajar sebesar 0,494 dan hasil belajar sebesar 0,077. Dapat dikatakan data hasil penelitian terdistribusi normal karena lebih besar dari $\alpha(0,05)$.

Tabel 2. Tests of Normality

\begin{tabular}{lccc}
\hline & \multicolumn{3}{c}{ Shapiro-Wilk } \\
\hline & Statistic & df & Sig. \\
Keterampilan Metakognititf & .954 & 31 & .199 \\
Minat Belajar & .969 & 31 & .494 \\
Hasil Belajar & .939 & 31 & .077 \\
\hline
\end{tabular}

\section{Uji Hipotesis}

Penelitian ini menerapkan hipotesis : adanya hubungan yang positif dan signifikan antara keterampilan metakognitif dan minat belajar dengan hasil belajar siswa pada materi kesetimbangan kimia submateri pergeseran kesetimbangan baik secara parsial ataupun simultan.

Tabel 3. Model Summary

\begin{tabular}{ccrcc}
\hline Model & $\mathrm{R}$ & $\mathrm{R}$ & $\begin{array}{c}\text { Adjusted } R \\
\text { Square }\end{array}$ & $\begin{array}{c}\text { Std. Error of the } \\
\text { Square }\end{array}$ \\
\hline 1 & $.875^{\mathrm{a}}$ & .766 & .749 & 4.26884 \\
\hline
\end{tabular}

Tabel model summary menunjukkan $\mathrm{R}$ square $=0,766$, artinya hasil belajar siswa dipengaruhi oleh keterampilan metakognitif dan minat belajarnya, dengan besar pengaruh sebesar 76,6\% dan 23,4\% dipengaruhi oleh aspek lain diluar variabel penelitian.

Pengaruh variabel independen terhadap variabel dependen secara parsial dapat dianalisis dengan uji $\mathrm{T}$.

Tabel 4. Coefficient

\begin{tabular}{|c|c|c|c|c|c|c|}
\hline \multicolumn{2}{|c|}{ Model } & \multicolumn{2}{|c|}{$\begin{array}{c}\text { Unstandardized } \\
\text { Coefficients }\end{array}$} & \multirow{2}{*}{$\begin{array}{c}\text { Standardized } \\
\text { Coefficients }\end{array}$} & \multirow[t]{2}{*}{$\mathrm{t}$} & \multirow[t]{2}{*}{ Sig. } \\
\hline & & B & Std. Error & & & \\
\hline \multirow[t]{4}{*}{1} & (Constant) & 36.109 & 8.551 & & 4.223 & .000 \\
\hline & Keterampilan & .446 & .066 & .726 & 6.717 & .000 \\
\hline & Metakognititf & & & & & \\
\hline & Minat Belajar & .276 & .126 & .237 & 2.193 & .037 \\
\hline
\end{tabular}

Berdasarkan tabel coefficient, maka persamaan regresi untuk hipotesis yaitu :

$$
\mathrm{Y}=36,109+0,446 \mathrm{X}_{1}+0,276 \mathrm{X}_{2} \text {. }
$$

Dari tabel koefisien dapat diuraikan bahwa :

a) Konstanta sebesar 36,109 dan bernilai positif, artinya bahwa semua variabel independen sama dengan nol (0), maka hasil belajar siswa dalam kondisi positif (baik) dan menunjukkan hasil belajarnya dalam kondisi normal.

b) Koefisien regresi keterampilan metakognitif sebesar 0,446 dan bernilai positif, yang artinya keterampilan metakognitif siswa mempengaruhi hasil belajarnya secara positif (baik) dengan peningkatan sebesar 0,446 satuan.

c) Koefisien regresi minat belajar sebesat 0,276 dan bernilai positif, yang artinya minat belajar siswa mempengaruhi hasil belajarnya secara positif (baik) dengan peningkatan sebesar 0,276 satuan. 
d) Pada uji $\mathrm{T}$ didapat $\mathrm{T}_{\text {hitung }}$ keterampilan metakognitif $\left(\mathrm{X}_{1}\right)$ bernilai $4,233>\mathrm{T}_{\text {tabel }}$ $(2,04841)$ dengan signifikasi $0,000<0,05$ artinya keterampilan metakognitif berpengaruh positif dan signifikan terhadap hasil belajar.

e) Pada uji $T$ didapat $T_{\text {hitung }}$ minat belajar $\left(X_{2}\right)$ bernilai $0,276>T_{\text {tabel }}(2,04841)$ dengan signifikasi $0,000<0,05$ artinya minat belajar berpengaruh positif dan signifikan terhadap hasil belajar.

Pengaruh variabel independen terhadap variabel dependen secara simultan dapat dianalisis dengan uji F.

Tabel 5. ANOVA

\begin{tabular}{llrrrrr}
\hline Model & & Sum of Squares & $\mathrm{df}$ & \multicolumn{1}{c}{$\begin{array}{c}\text { Mean } \\
\text { Square }\end{array}$} & F & Sig. \\
\hline 1 & Regression & 1667.175 & 2 & 833.587 & 45.744 & $.000^{\mathrm{b}}$ \\
& Residual & 510.245 & 28 & 18.223 & & \\
& Total & 2177.419 & 30 & & & \\
\hline
\end{tabular}

Berdasarkan tabel ANOVA, diketahui nilai $F_{\text {hitung }}$ sebesar 45,744 $>F_{\text {tabel }}(3,33)$ dengan signifikasi $0,000<0,05$, artinya secara simultan keterampilan metakognitif dan minat belajar berpengaruh positif dan signifikan terhadap hasil belajar siswa.

Berdasarkan analisa yang sudah dilakukan, dapat dijelaskan bahwa keterampilan metakognitif dan minat belajar berpengaruh positif dan signifikan terhadap hasil belajar siswa, hal ini sependapat dengan penelitian dari Nurdianti Putri et al., (2018). Selanjutnya Sonyinga et al., (2019) juga menyebutkan kesadaran metakognitif memiliki pengaruh terhadap hasil belajar siswa, didukung oleh Fitria et al., (2020) yang menyatakan kesadaran metakognitif siswa akan berbanding lurus dengan hasil belajarnya. Hasil analisis secara statistik juga didukung oleh temuan penelitian ini bahwa keterampilan metakognitif secara klasikal berada pada kategori sedang. Temuan tersebut dapat dirinci, untuk indikator menuliskan tujuan belajar (planning skills) berada pada kategori baik, memikirkan dan menuliskan yang diketahui dan tidak diketahui (planning skills) berada pada kategori sangat baik, memecahkan masalah tambahan (monitoring skills) berada pada kategori baik, dan memeriksa ulang tujuan belajar apakah sudah tercapai semua (evaluating skills) berada pada kategori sedang. Didukung dengan data angket MAI yang menyebutkan bahwa keterampilan metakognitif secara klasikal berada pada kategori baik.

Data pengaruh minat belajar sependapat dengan penelitian dari Damayanti \& Jirana, (2018) dan B.Mesra, (2018) yang menyebutkan bahwa hasil belajar kimia siswa dipengaruhi oleh minat belajarnya. Penelitian lain dari Rozikin et al., (2018) dan Nurhasanah \& Sobandi., (2016) juga menyebutkan bahwa minat belajar dan hasil belajar saling berkorelasi positif dan signifikan. Pada penelitian ini minat belajar secara klasikal berada pada kategori baik, untuk indikator ketertarikan dalam membaca buku kimia, perhatian dalam belajar kimia, dan keaktifan siswa pada pelajaran kimia berada pada kategori baik, sedangkan pengetahuan kimia siswa berada pada kategori sangat baik. Hasil belajar yang didapat dari penelitian ini berada pada kategori sangat baik dengan rata-rata secara klasikal sebesar 86,77.

\section{Kesimpulan}

Hasil penelitian ini menyimpulkan bahwa terdapat hubungan positif dan signifikan antara keterampilan metakognitif dan minat belajar terhadap hasil belajar siswa pada submateri pergeseran kesetimbangan secara parsial dan simultan. Pengaruh keterampilan metakognitif 
dan minat belajar secara simultan sebesar $76,6 \%$ terhadap hasil belajar siswa, sedangkan $23,4 \%$ dipengaruhi oleh aspek lain diluar variabel penelitian.

\section{Saran}

Adapun saran terkait hasil penelitian ini antara lain adalah; (1) Bagi guru agar dapat menerapkan proses pembelajaran yang menekankan pada pelatihan keterampilan metakognitif dan peningkatan minat belajar siswa, sebagai upaya untuk meningkatkan hasil belajar siswa; (2) Bagi siswa diharapkan untuk dapat memahami cara belajar yang sesuai, lebih aktif selama pembelajaran dan mempertahankan dan meningkatkan minat belajarnya; (3) Bagi sekolah diharapkan dapat menyediakan fasilitas pendukung untuk mengembangkan keterampilan metakognitif maupun keterampilan berpikir lainnya yang dimiliki siswa, serta untuk meningkatkan minat belajar siswa guna meningkatkan hasil belanjarnya; dan (4) Bagi peneliti berikutnya dapat menambahkan variabel independen dan subjek lain, penelitian juga bisa diperluas dengan penambahan bidang hasil belajar selain kognitif, yaitu bidang afektif dan psikomotorik.

\section{Daftar Pustaka}

Abdullah, R. (2017). Urgensi Metakognisi dalam Pencapaian Hasil Belajar Kimia di SMA. Lantanida Journal, 5(2), 93-196.

Abu-Hamdan, T., \& Khader, F. (2014). Alignment of Intended Learning Outcomes with Quellmalz Taxonomy and Assessment Practices in Early Childhood Education Courses. Journal of Education and Practice, 5(29).

Amanda, M. H., Haryani, S., Mahatmant, F. W., \& Marsini. (2020). Analisis Kemampuan Metakognisi Siswa melalui Penggunaan Lembar Kerja Siswa Berbasis Discovery Learning. Jurnal Inovasi Pendidikan Kimia, 14(1), 2468 - 2478.

Amin, E. V., Andayani, Y., \& Sukib, S. (2018). Hubungan antara Minat Belajar dan Kebiasaan Belajar terhadap Hasil Belajar Kimia Siswa Kelas XI IPA SMA Mataram Tahun Ajaran 2017/2018. Chemistry Education Practice, 1(1), 13-19.

Azizah, U., Nasrudin, H., \& Mitarlis. (2019). Metacognitive Skills: A Solution in Chemistry Problem Solving. Journal of Physics: Conference Series.

B, M. (2018). Pengaruh Minat Belajar dan Jam Belajar terhadap Prestasi Belajar Siswa (Studi Kasus : SMAN 1 Pangururan). Jurnal Manajemen Tools, 10(2), 31-38.

Damayanti, M., \& Jirana, J. (2018). Pengaruh Model Pembelajaran dan Minat Belajar Terhadap Hasil Belajar Kimia Peserta Didik Kelas XI IPA SMAN 1 Tinambung. JURNAL SAINTIFIK, 4(1), 47-53.

Fitria, L., Jamaluddin, \& Artayasa, I. P. (2020). Analisis Hubungan antara Kesadaran Metakognitif dengan Hasil Belajar Matematika dan IPA Siswa SMA di Kota Mataram. Jurnal Kependidikan: Jurnal Hasil Penelitian Dan Kajian Kepustakaan Di Bidang Pendidikan, Pengajaran Dan Pembelajaran, 6(1), 147-155.

Hemayanti, K., Muderawan, I., \& Selamat, I. (2020). Analisis Minat Belajar SIswa Kelas XI MIA pada Mata Pelajaran Kimia. Jurnal Pendidikan Kimia Indonesia, 4(1), 20-25.

Iskandar, S. M. (2014). Pendekatan Keterampilan Metakognitif dalam Pembelajaran Sains di Kelas. Erudio Journal of Educational Innovation, 2(2), 13-20. 
Iskandar, Y. (2001). Test Bakat, Minat, Sikap dan Personaliti MMPI-DG. Jakarta: Yayasan Dharma Graha.

Jayapraba, G., \& Kanmani, M. (2013). Metacognitive awareness in science classroom of higher secondary students. International Journal on New Trends in Education and Their Implications, 4(7), 49-56.

Klassen, S., \& Klassen, C. F. (2014). The Role of Interest in Learning Science Through Stories. Interchange, 45(3-4), 133-151.

Kpolovie, P. J. (2014). Academic Achievement Prediction: Role of Interest in Learning and Attitude towards School. International Journal of Humanities Social Sciences and Education (IJHSSE), 1(11), 73-100.

Laa, N., Winata, H., \& Meilani, R. I. (2017). Pengaruh model pembelajaran kooperatif tipe student teams achievement division terhadap minat belajar siswa. JURNAL PENDIDIKAN MANAJEMEN PERKANTORAN, 2(2), 139-148.

Mahmuda, S., \& Azizah, U. (2020). Penerapan Model Pembelajaran Kooperatif Tipe NHT untuk Melatihkan Keterampilan Metakognitif pada Materi Asam Basa Kelas XI SMAN 1 Waru. UNESA Journal of Chemical Education, 9(3), 417-426.

Mølstad, C. E., \& Karseth, B. (2016). National curricula in Norway and Finland: The role of learning outcomes. European Educational Research Journal, 15(3), 329-344.

Mustapa, Cawang, \& Qurbaniah, M. (2017). ubungan antara Kesadaran Metakognisi dengan Hasil Belajar Siswa pada Mata Pelajaran Kimia Kelas XI SMA Muhammadiyah 1 Ketapang. Ar-Razi Jurnal Ilmiah, 5(2), 204-214.

Nurdianti Putri, N. K., Danial, M., \& Arsyad, N. (2018). Pengaruh Sikap, Konsep Diri, dan Kesadaran Metakognitif terhadap Hasil Belajar Kimia Peserta Didik kelas XI MIA SMAN di Kecamaran Ujung Bulu Kabupaten Bulukumba. Chemistry Education (CER) Pend. Kimia PPs UNM, 1(2), 73-89.

Nurhasanah, S., \& Sobandi., A. (2016). Minat Belajar sebagai Determinan Hasil Belajar Siswa. JURNAL PENDIDIKAN MANAJEMEN PERKANTORAN, 1(1), 128-135.

Olufemi Adodo, S., \& L. O. Gbore. (2012). Prediction of attitude and interest of science students of different ability on their academic performance in basic science. International Journal of Psychology and Counselling, 4(6), 68-72.

Pulmones, R. (2007). Learning Chemistry In A Metacognitive Environment. The Asia Pasific: Education Researcher, 16(2), 165-183.

Riduwan. (2011). Dasar-Dasar Statistika. Bandung: Alfabeta.

Rozikin, S., Amir, H., \& Rohiat, S. (2018). Hubungan Minat Belajar Siswa dengan prestasi belajar Siswa Pada Mata Pelajaran Kimia di SMA Negeri 1 Tebat Karai dan SMA Negeri 1 Kabupaten Kepahiang. Alotrop, Jurnal Pendidikan Dan Ilmu Kimia, 2(1), 78-81.

Saputri, R. J., Sumpono, S., \& Elvia, R. (2018). Perbandingan Hasil dan Minat Belajar Siswa Kelas X IPA Menggunakan Model Pembelajaran Kooperatif Snowball Throwing dan 
Talking Stick pada Kurikulum-2013 di SMAN 10 Kota Bengkulu. Alotrop, Jurnal Pendidikan Dan Ilmu Kimia, 2(2), 166-174.

Schraw, G., \& Dennison, R. S. (1994). Assesing Metacognitive awareness. Contemporary Educational Psychology, 19, 460-470.

Sinaga, M., \& Silaban, S. (2020). Implementasi Pembelajaran Kontekstual untuk Aktivitas dan Hasil Belajar Kimia Siswa. Gagasan Pendidikan Indonesia, 1(1), 33-40.

Sonyinga, D., Danial, M., \& Herawati, N. (2019). Pengaruh Model Pembelajaran dan Kesadaran Metakognisi terhadap Hasil Belajar Peserta Didik. Chemistry Education Review, Pendidikan Kimia PPs UNM, 3(1), 31-41.

Straus, S., Graham, I. D., \& Tetroe, J. (2013). Translation in Health Care: Moving from Evidence to Practice. London: BMJ Publishing Group.

Sugiyono. (2012). Metode Penelitian Kuantitatif, Kualitatif dan R\&D. Bandung: Alfabeta. 